\title{
ANÁLISE HIDROLÓGICA E SOCIOAMBIENTAL DA BACIA HIDROGRÁFICA DO CÓRREGO ROMÃO DOS REIS, VIÇOSA-MG ${ }^{1}$
}

Genice Vieira Santos ${ }^{2}$, Herly Carlos Teixeira Dias ${ }^{3}$, Ana Paula de Souza Silva ${ }^{4}$ e Maria de Nazaré Costa de Macedo ${ }^{4}$

\begin{abstract}
RESUMO - O objetivo deste trabalho foi analisar os aspectos hidrológico e socioeconômico da bacia hidrográfica do córrego Romão dos Reis, que se localiza no Município de Viçosa, na região da Zona da Mata do Estado de Minas Gerais. O estudo enfatizou o uso e ocupação da terra como fatores determinantes na análise da qualidade da água, além dos fatores físicos da bacia. Esta foi dividida em sub-bacias, o que possibilitou a escolha de locais representativos para coleta e análise de dados. Coletaram-se os dados referentes a vazão, qualidade da água, elevações, precipitação, uso do solo, tipo de solo e aspectos sociais e econômicos. Para a elaboração dos mapas, utilizou-se o modelo digitalizado, construído a partir de mosaicos e fotos aéreas da região, na escala de 1:30.000. As informações sobre o número de moradores e proprietários, assim como os seus respectivos sistemas de cultivos e ocupação na bacia, foram obtidas por meio de entrevistas semi-estruturadas, visando melhor compreender a organização social e o manejo de uso da terra das propriedades. Foram apontados indicadores de degradação, assim como estratégias de manejo adequadas à melhoria ambiental, que venham contribuir e garantir a sustentabilidade da bacia.
\end{abstract}

Palavras-chave: Bacia hidrográfica, manejo e hidrologia floresta.

\section{THE HYDROGRAPHIC WATERSHED OF ROMÃO DOS REIS STREAM, VIÇOSA-MG}

\begin{abstract}
This study was carried out to analyze the hydrological and socioeconomic aspects in the hydrographic watershed of Romão dos Reis stream in Viçosa county, Zona da Mata region, Minas Gerais State. In this study, the land use and occupation are emphasized as determinant factors for analyzing water quality, besides physical factors. The watershed was divided into sub-watersheds enabling to choose the representative sites for data collection and analysis. Data on flow rate, water quality, relief, precipitation, landscape (top, hillside and terrace), soil type, social and economic aspects were collected. A digitalized model built from mosaics and aerial photos of the area at 1:30.000 scale was used to draw up the maps. Information on the number of residents and owners as well as their respective cropping systems and watershed occupation were obtained by applying semi-structured interviews in order to get a better understanding of the social organization and management of land use in the farms. Degradation indicators were pointed out, as well as suitable management strategies for environmental improvement that would contribute and ensure the sustainability of the watershed.
\end{abstract}

Keywords: Hydrographic watershed, management and forest hydrology.

\footnotetext{
${ }^{1}$ Recebido em 30.05.2006 e aceito para publicação em 25.01.2007.

${ }^{2}$ Engenheira Florestal pela Universidade Federal de Viçosa (UFV) - SRI02/HFA - Bloco D Ap. 106 - CEP 70658-900 Brasília, DF.E-mail: <genice.santos@bol.com.br>.

${ }^{3}$ Departamento de Engenharia Florestal da UFV, 36570.000 Viçosa-MG. E-mail: <herly@ ufv.br>.

${ }^{4}$ Programa de Pós-graduação em Ciência Florestal da UFV. E-mail: <macedo.ac@ gmail.com>e < apdess@ yahoo.com.br>.
} 


\section{INTRODUÇÃO}

A interferência do homem no meio ambiente e a utilização inadequada das terras vêm gerando, ao longo do tempo, a insustentabilidade dos recursos naturais. O manejo irracional dos solos, muitas vezes, inviabiliza a produção e compromete o equilíbrio dos ecossistemas.

O ciclo degradador provocado por desmatamentos, exposição do solo às intempéries, intensa utilização de insumos e escoamento superficial gera impactos negativos decorrentes da erosão, fato esse agravado por um difícil e custoso controle. Para minimizar tais efeitos, é necessário estabelecer um sistema de conservação do solo, associado à observação do uso do solo na paisagem e da movimentação da água, em uma situação específica de cada área.

Nesse contexto, torna-se evidente a necessidade de considerar as interações entre os setores social, econômico e ambiental, a fim de conduzir estratégias de sustentabilidade. Os fatores culturais, sociais e econômicos devem ser observados e analisados, tendo como indicadores a base dos recursos naturais que os sustenta. Para isso, a tipificação dos ambientes ocupados pelos sistemas dos agricultores impõe um conhecimento do ecossistema e um zoneamento baseado em critérios de produtividade e sustentabilidade, em face dos usos atuais, que se agreguem ao histórico da ocupação humana (VIVAN, 1998).

Para avaliar o possível efeito de qualquer perturbação numa bacia hidrográfica, é necessário conhecer, inicialmente, as características do ecossistema em suas condições naturais de equilíbrio, a fim de estabelecer comparações entre as condições hidrológicas e de qualidade da água no ecossistema natural e os ecossistemas nos quais ocorre ação direta do homem.

Para análise de ecossistemas, destacam-se algumas características, como clima, geomorfologia, solo, vegetação, deflúvio e evapotranspiração, que contribuirão para a quantificação do processo hidrológico da bacia e deverão ser relacionadas àquelas concernentes à quantidade, qualidade e dinâmica da água (ANIDO, 2002).

Um dos pilares do manejo sustentável se refere aos aspectos ecológicos, englobados no princípio de manutenção da integridade do ecossistema. No contexto da bacia, tal integridade envolve a manutenção de seu funcionamento hidrológico, o que significa perpetuar os processos hidrológicos (deflúvio, regime de vazão e qualidade da água) e manter sua capacidade natural de suporte produtivo (biogeoquímica), além da perpetuação de diversidade ecológica (vegetação ciliar, protegendo as zonas ripárias, reservas de vegetação natural) e sua estabilidade e capacidade de resistir a mudanças ambientais (LIMA, 1986).

Do ponto de vista hidrológico, o deflúvio de uma bacia pode ser considerado como produto residual do ciclo hidrológico, o qual é influenciado por três grandes grupos de fatores: clima, fisiografia, cobertura e uso do solo (RANZINI, 2002).

Ao mover-se nos diferentes compartimentos de uma bacia, a água tem sua qualidade alterada, e qualquer modificação nas condições da bacia hidrográfica pode causar alterações significativas na qualidade da água (ARCOVA e CICCO, 1999).

Dentre outros parâmetros significativos de avaliação da qualidade da água, a turbidez, a cor e a concentração de sedimentos em suspensão são relevantes, tanto no que diz respeito aos processos de tratamento da água para fins de abastecimento público quanto para o monitoramento das práticas de manejo.

Conforme Cogo (1988), por meio da análise dos fatores que influenciam a erosão hídrica do solo definese a importância relativa de cada um dos fatores da equação universal de perda do solo e constata-se que os fatores sobre os quais o homem pode, facilmente, intervir para fins de controle da erosão do solo são o manejo da cultura e o manejo da terra, pois os outros, como a erosividade da chuva, erodibilidade intrínseca do solo e comprimento e grau do declive, são impossíveis de transformação antrópica.

Diante desse contexto, este trabalho teve como objetivo analisar os aspectos hidrológico e socioeconômico da bacia hidrográfica do córrego Romão dos Reis, que está situada no Município de Viçosa, localizado na região da Zona da Mata do Estado de Minas Gerais.

\section{MATERIAL E MÉTODOS}

\subsection{Localização e caracterização da área}

A bacia hidrográfica do córrego Romão dos Reis localiza-se nas coordenadas métricas UTM E 718400 a E 720000 e N 7699800 a N 7701300, fuso 23. Possui uma área de 230 há, aproximadamente. Está inserida na bacia hidrográfica do ribeirão São Bartolomeu (Figura 1). 


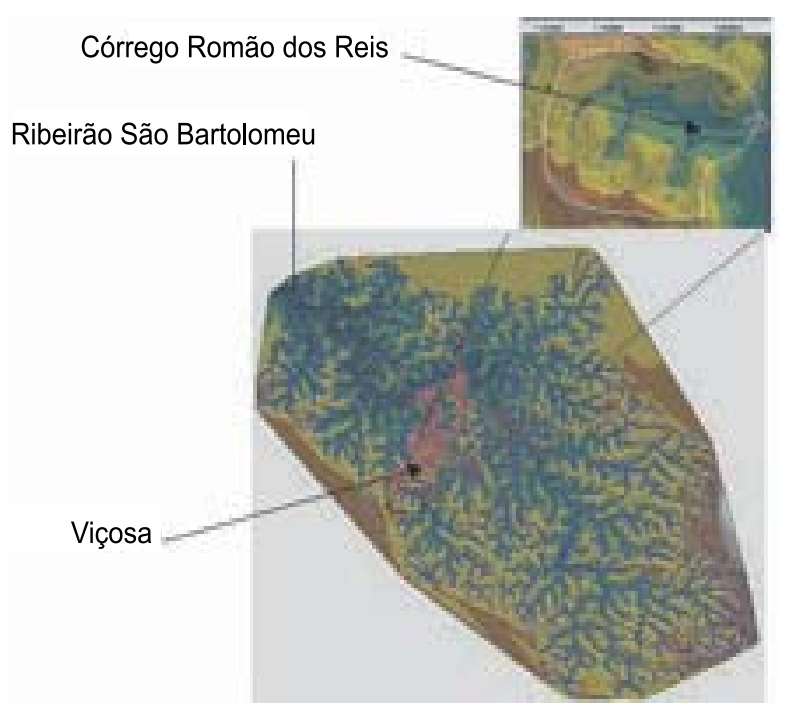

Figura 1 - Imagem representativa da localização da bacia hidrográfica Romão dos Reis (em destaque), inserida na bacia hidrográfica do ribeirão São Bartolomeu, no Município de Viçosa, MG.

Figure 1-Image representing the location of the hydrographic watershed Romão dos Reis (in detail) within the hydrographic watershed of São Bartolomeu creek, in Viçosa county, MG.

O clima é classificado como tropical de altitude, diferindo, principalmente, entre as estações de inverno e verão com seca e muita chuva, respectivamente, sendo do tipo mesotérmico úmido Cwa, segundo a classificação de Köppen (GOLFARI, 1975). A precipitação média anual é de 1.221 mm (DNM, 1992).

A vegetação original encontra-se em pequenos fragmentos florestais e caracteriza-se como Floresta Estacional Semidecidual. O solo da bacia tem o predomínio da classe Latossolo Vermelho-Amarelo, não diferindo de toda a região do município. Com relação ao sistema de uso da terra, destacam-se plantios de café, em alguns casos, culturas anuais, como o feijão, milho e cana, considerando-se que a maioria das áreas é formada por pastagem degradada.

Esse processo de desmatamento tem resultado em um conjunto de problemas ambientais, como: extinção de várias espécies da fauna e flora, mudanças climáticas locais, erosão do solo, eutrofização e assoreamento dos cursos de água, além de colocar em risco a diversidade das faunas aquáticas (FERREIRA e DIAS, 2004; PINTO et al., 2005).

\subsection{Mapeamento}

A área foi dividida em sub-bacias, possibilitando a confecção de um mapa que facilitou a escolha de locais representativos, conforme a distribuição das nascentes (bacias de primeira ordem) para a coleta e análise dos dados.

Com o intuito de ilustrar e identificar as características físicas e ambientais, elaboraram-se mapas com a utilização de modelos digitalizados, fornecidos e confeccionados no Laboratório de Geoprocessamento do Departamento de Solos, Universidade Federal de Viçosa, sendo eles construídos a partir de mosaicos e fotos aéreas da região na escala de 1:30.000 de 1987.

Para correção das coordenadas UTM foram marcados quatro pontos no campo, os quais eram facilmente identificados no mapa. As coordenadas foram adquiridas por meio de um Global Position System (GPS), modelo GPS II, marca Garmin.

\subsection{Morfometria}

Utilizando fotos aéreas e cartas topográficas com escala de 1:50.000, bem como um estereoscópio de espelhos (oculares 3x de aumento), foi possível identificar, medir e calcular parâmetros morfométricos, como a densidade de drenagem, o fator de forma, os índices de circularidade e compacidade, a razão de elongação, a razão de bifurcação, a orientação e a altitude média.

A delimitação da bacia foi realizada por meio dessas fotos aéreas e dos mapas digitalizados. Após delimitada, a área da bacia hidrográfica foi determinada por meio de leituras com um planímetro digital DIGIPLAN, marca Haff, modelo Roll-planimeter $\mathrm{n}^{\circ} 331$, sobre a carta topográfica, escala 1:50.000.

\subsection{Vazão}

As medições da vazão foram realizadas nas saídas de cada bacia de primeira ordem (ou bacia de cabeceira), semanalmente, durante o período de setembro a novembro de 2004. Utilizou-se o método direto de medição da vazão, empregando-se balde e cronômetro. Após a coleta das informações, realizou-se a análise exploratória dos dados, utilizando o cálculo das médias de cinco leituras de cada ponto escolhido.

\subsection{Análise de qualidade da água}

Para análise de qualidade da água, foram escolhidos cinco locais que representavam cada sub-bacia, incluindo um ponto de contribuição na saída, representando toda

R. Árvore, Viçosa-MG, v.31, n.5, p.931-940, 2007 
a sub-bacia. As amostras foram coletadas, a fim de analisar a condutividade elétrica, o oxigênio dissolvido e a temperatura no local, sendo, então, levadas para o laboratório da estação de tratamento de água da Universidade Federal de Viçosa. Determinaram-se a turbidez, a cor e o pH. Para esse procedimento, foram usados os seguintes aparelhos: condutivímetro DM3, DIGIMED; oxímetro DM4, DIGIMED; 2100P turbidimeter, marca HACH; PHmetro DM20, DIGIMED; e Nessler Quanti 200, marca Policontrol.

\subsection{Aspectos socioeconômicos}

Para a coleta de informações sobre os aspectos socioeconômicos, a população amostrada constituise de sete produtores rurais. Vale ressaltar que reside na bacia um total de sete famílias, portanto a população amostrada foi de $100 \%$.

Foram utilizadas entrevistas semi-estruturadas com os moradores e proprietários das terras. Nessa modalidade de entrevista, utilizou-se um roteiro previamente elaborado, que funciona apenas como um fio condutor das entrevistas e não como um questionário a ser seguido à risca. Essa técnica facilita a maior participação dos produtores rurais e estimula a espontaneidade das informações (OLIVEIRA e OLIVEIRA, 1982).

O roteiro constou de questões concernentes à atividade agrícola, tamanho da propriedade, uso da água, dificuldades encontradas nas propriedades, anseios por melhoria de vida, relações comunitárias, processo de ocupação e áreas de preservação permanente.

\section{RESULTADOS E DISCUSSÃO}

A partir da base cartográfica, quatro sub-bacias de cabeceiras foram identificadas e delimitadas, conforme a composição de cores apresentada na Figura 2.

\subsection{Aspectos socioeconômicos das sub-bacias}

A sub-bacia 0 apresentou a maior densidade demográfica, porque englobava parte do bairro denominado Romão dos Reis, que não foi enquadrado no estudo, por possuir características urbanas, diferindo do enfoque por ser em área rural (Figura 3a).

Na divisão de terras existem cinco propriedades rurais, com área de 1,0 a 25 alqueires aproximadamente, em que há mais próxima à nascente possui 1,0 alqueire (3,0 ha), com o morador residindo a mais de 30 anos no local, juntamente com seus agregados. No entanto, a maior extensão da sub-bacia 0 está coberta por uma propriedade que possui 25 alqueires.

A agricultura desenvolvida no local é basicamente de subsistência (cana, feijão, milho e plantio de café) e com manejo de solo realizado com baixo nível tecnológico. Existe apenas uma propriedade com pomar ao redor da casa, plantas ornamentais e frutíferas, com o pasto sendo manejado para a criação de gado.

Verificou-se que a sub-bacia 1 está dividida por duas propriedades. Esta área é peculiar, pois não possui construção civil e é ocupada por pastagem. Observouse que a estrada nesta área tem contribuído com o processo erosivo expondo o horizonte $\mathrm{C}$.

As porções destinadas às Áreas de Preservação Permanente (APPs) nos topos de morros estão em bom estado de conservação, apresentando, também, mata ciliar no prolongamento do curso de água, exceto nos açudes, constituindo dois represamentos dominados por taboa (Typha sp.) (Figura 3b).

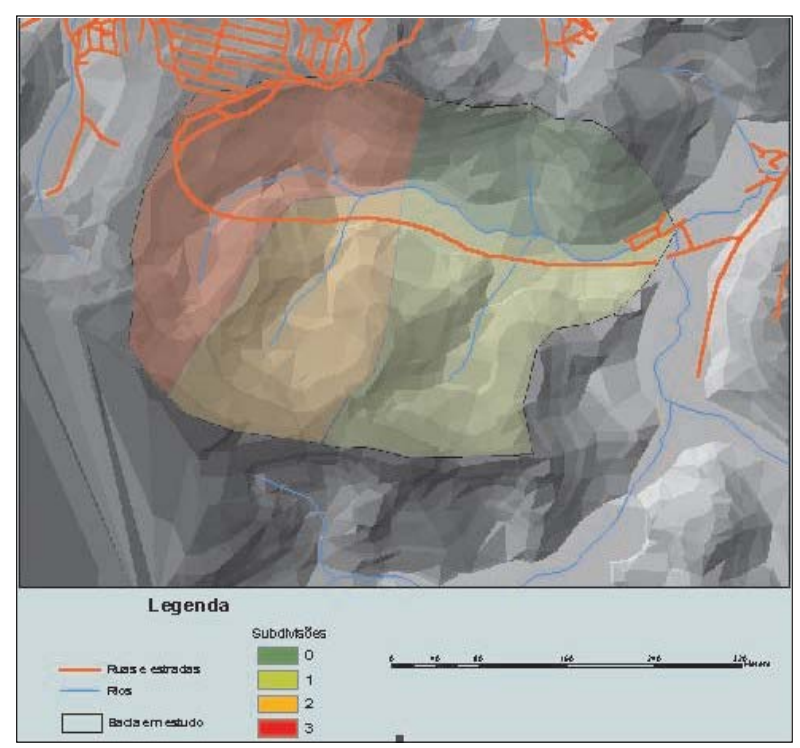

Figura 2 - Mapa mostrando a divisão da bacia hidrográfica do córrego Romão dos Reis em sub-bacias (subdivisões $0,1,2$, e 3 ).

Figure 2-Map showing the division of the hydrographic watershed of Romão dos Reis stream into subwatersheds (subdivisions $0,1,2$ and 3). 

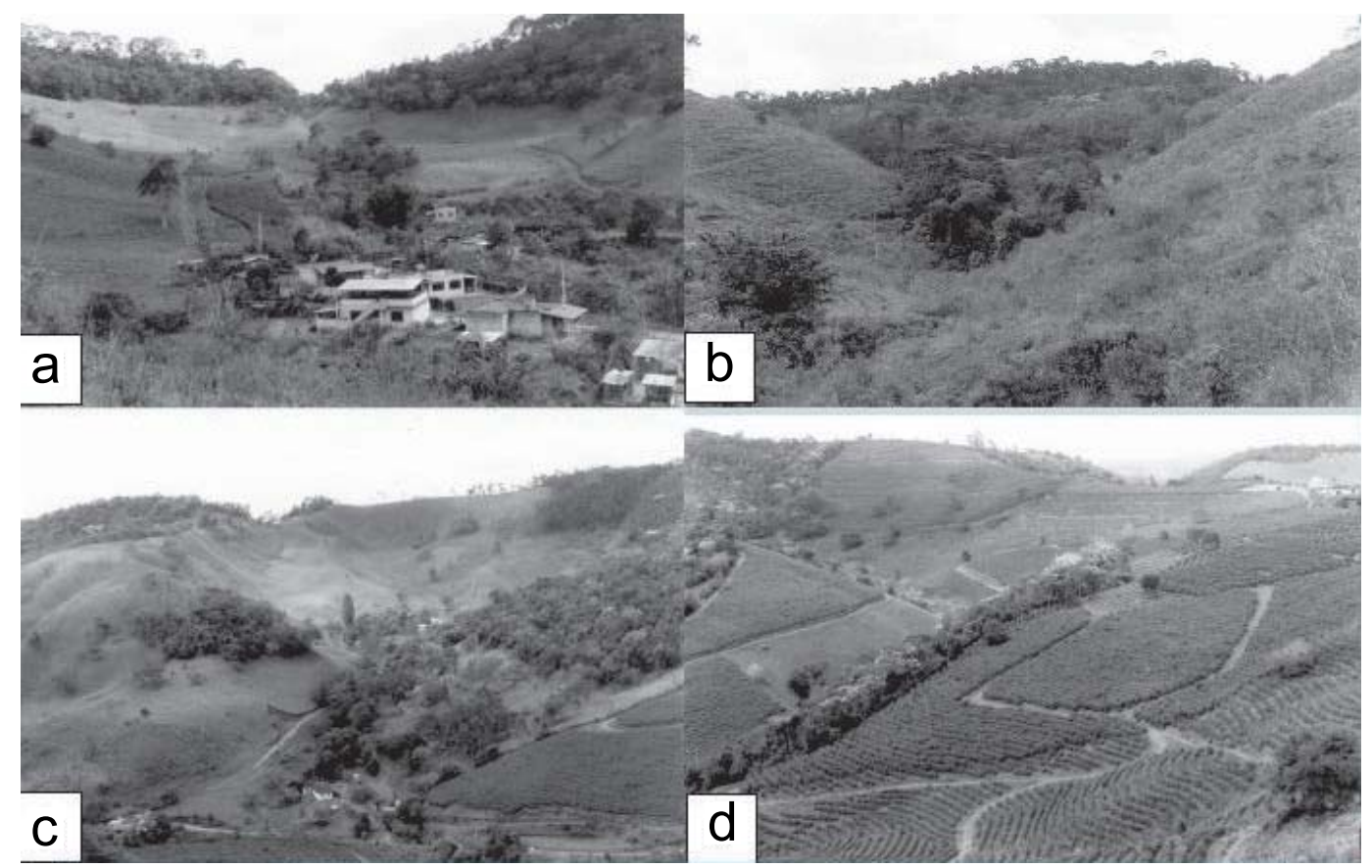

Figura 3 - Fotos com vista parcial das sub-bacias 0 (a), 1 (b), 2 (c) e 3 (d) que compõem a bacia hidrográfica do córrego Romão dos Reis.

Figure 3 - Photos with partial view of the sub-watersheds $O(a), 1(b), 2(c)$ and $3(d)$ composing the hydrographic watershed of Romão dos Reis stream.

A sub-bacia 2 é a segunda mais habitada. Dividese em três propriedades, sendo uma com nove casas alugadas para estudantes de outras cidades, que moram em repúblicas. O mais antigo morador residia no local há 25 anos, não possuía o título da terra e trabalhou durante muitos anos como meeiro na plantação de propriedades vizinhas.

No que se refere à questão ambiental, é uma das regiões da bacia que apresentam maiores problemas quanto ao manejo. A área onde existe pastagem deveria ser Área de Preservação Permanente, pelo fato de a sua declividade ser superior a $45^{\circ}$.

Outros pontos com elevado grau de degradação são: as estradas abandonadas e divisores topográficos. Nas estradas ocorre impacto negativo decorrente do voçorocamento, em virtude da retirada de terra para a construção de barragem. A falta de cobertura nos topos de morro indica a predisposição à erosão, em decorrência do maior escoamento superficial, e decréscimo da captação de água na sub-bacia. Vale ressaltar que a queimada é uma das práticas utilizadas no manejo da pastagem. Nessa sub-bacia existem duas nascentes, sendo uma não representada no mapa por não atender à demanda de água em todas as casas (Figura 3c e Figura 4).

Na sub-bacia 3 (Figura 3d), a característica marcante é o plantio comercial extensivo de café, com estradas recortando a plantação entre as curvas de nível. Em geral, a declividade é bem acentuada, principalmente em um dos pontos de maior altitude da bacia.

Outro fator relevante é a expansão do Bairro de Nova Viçosa, limítrofe no topo, onde se encontram vários moradores, inclusive os caseiros, que trabalhavam para os donos das lavouras, proprietários não residentes no local. Muitos moradores do bairro trabalhavam na plantação, sendo, em sua maioria, as mulheres que realizavam a colheita. Essa é a área com maior produtividade, que gera mais emprego e possui importante valor social.

\subsection{Produção de água das sub-bacias}

O comportamento hidrológico das sub-bacias 1, 2 e 3 (Figura 2), identificado em razão da pouca variação das vazões no período de setembro a novembro de 2004, é representado na Figura 5.

R. Árvore, Viçosa-MG, v.31, n.5, p.931-940, 2007 


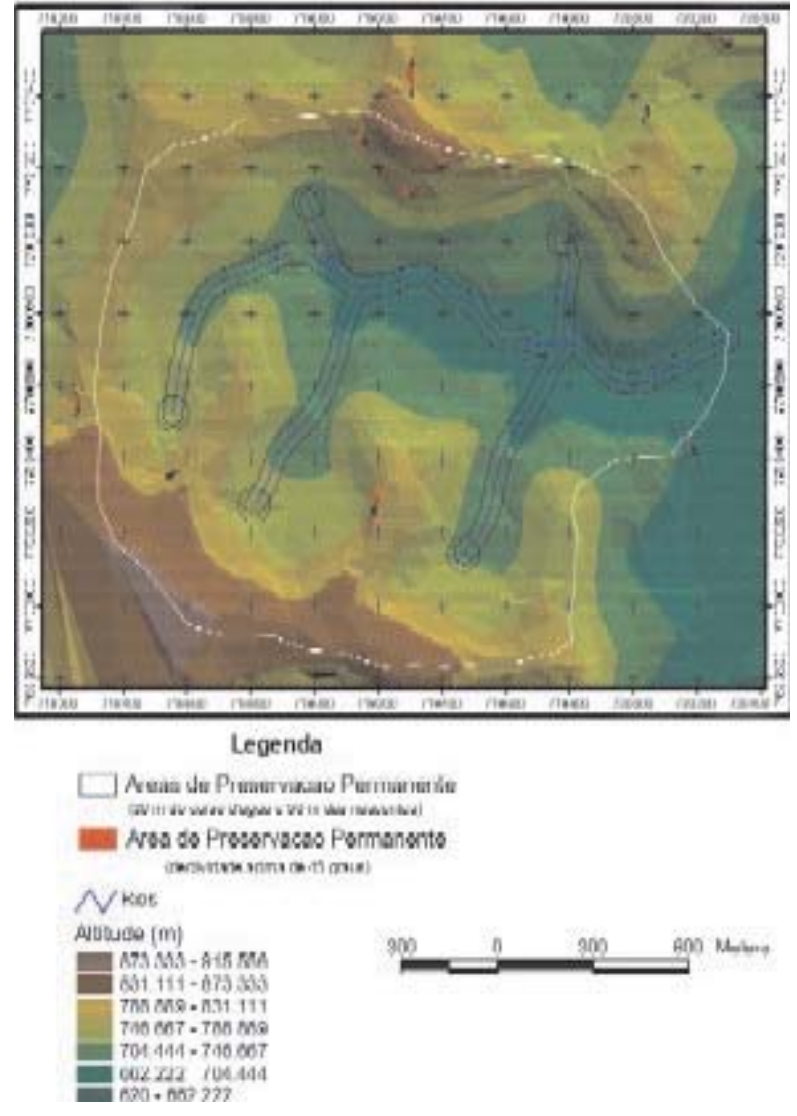

Figura 4 - Mapa das Áreas de Preservação Permanente da bacia hidrográfica do córrego Romão dos Reis, 2004.

Figure 4-Map of Permanent Preservation Areas in the hydrographic watershed of Romão dos Reis stream, 2004.

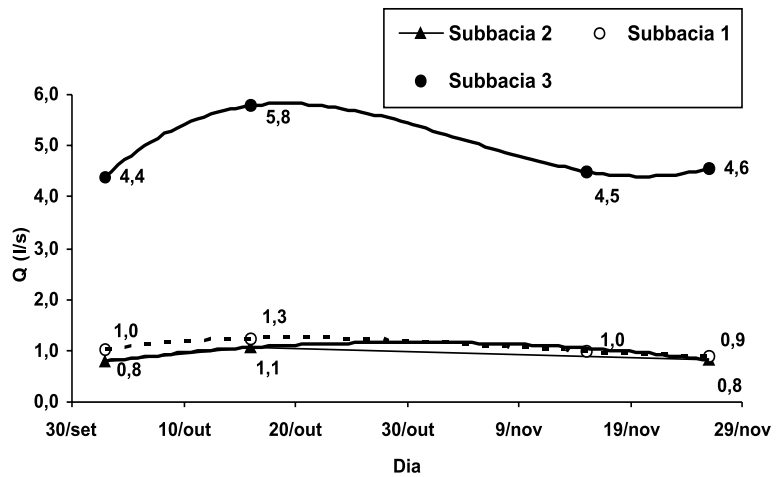

Figura 5 - Gráfico de variação da vazão das nascentes do córrego Romão dos Reis, Município de Viçosa, MG, 2004.

Figure 5 - Graph of the flow rate variation of Romão dos Reis stream watersheds, in Viçosa county, MG, 2004.

R. Árvore, Viçosa-MG, v.31, n.5, p.931-940, 2007
A vazão da sub-bacia 0 não pôde ser monitorada devido à falta de condições apropriadas para leitura. As nascentes das sub-bacias 1 e 2 apresentaram menor vazão no período avaliado, porém maior estabilidade entre as medições. A nascente da subbacia 3 teve valores de vazão bastante superiores ao do grupo anterior em razão, provavelmente, do estado de conservação da sub-bacia e do cultivo de culturas perenes em nível, o que permite maior infiltração de água no solo, embora tal fato não tenha sido comprovado neste estudo.

O ligeiro aumento da vazão no dia 16 de outubro pode ser explicado pela maior precipitação registrada nesse dia (14 $\mathrm{mm})$, conforme apresentado na Tabela 1 .

\subsection{Morfometria da bacia hidrográfica do córrego Romão dos Reis}

Os parâmetros utilizados na caracterização da bacia hidrográfica são apresentados na Tabela 2 . Existe forte relação da morfologia da bacia com clima e pedoforma. Trata-se de uma microbacia pouco ramificada, com baixa densidade de drenagem, refletindo as condições geomorfológicas e climáticas da região. Em geral, a bacia apresenta forma tendendo à quadrática, com fator de forma e índice de compacidade distantes da unidade, o que indica maior tempo de concentração do escoamento superficial até atingir a saída da bacia (TONELLO, 2005) e menores tendências a enchentes.

A orientação da bacia indica que o fluxo de água segue o sentido leste/oeste predominantemente, com a ressalva de que, nesse sentido, ocorre maior tempo de exposição à radiação solar ao longo do dia. Isso afeta, diretamente, as condições de evapotranspiração dentro da bacia.

A altitude média da bacia hidrográfica é de 785,7 $\mathrm{m}$, conforme a metodologia utilizada. Um estudo mais detalhado pode ser observado na distribuição hipsométrica da bacia, conforme a Figura 6. Observase que $50 \%$ da área da bacia encontrava-se acima de $800 \mathrm{~m}$ de altitude, e nesse caso a mediana da distribuição de altitude é bem próxima à altitude média, indicando uma distribuição homogênea das áreas por classe de altitude. 
Tabela 1 - Parâmetros climáticos da região. Dados coletados em novembro de 2004, na Estação Meteorológica da Universidade Federal de Viçosa

Table 1 - Climatic parameters of the region. Data collected in November 2004, at the Meteorological Station of the Universidade Federal de Viçosa

\begin{tabular}{|c|c|c|c|c|c|c|}
\hline \multirow[t]{2}{*}{ Dia } & \multirow[t]{2}{*}{ Precipitação(mm) } & \multirow[t]{2}{*}{ Umidade média (\%) } & \multirow[t]{2}{*}{ Temperatura $\left({ }^{\circ} \mathrm{C}\right)$} & \multicolumn{3}{|c|}{ Vento $(\mathrm{m} / \mathrm{s})$} \\
\hline & & & & $12 \mathrm{~h}$ & $18 \mathrm{~h}$ & $24 \mathrm{~h}$ \\
\hline \multicolumn{7}{|c|}{ Outubro } \\
\hline 03 & 2,2 & 84 & 20,2 & $\mathrm{~N} 2,0$ & SW 2,0 & 0,0 \\
\hline 04 & 17,2 & 96 & 16,8 & $\mathrm{~N} 0,7$ & W 0,8 & 0,0 \\
\hline 05 & 2,6 & 88 & 19,7 & 0,0 & $\mathrm{~N} 1,0$ & SW 1,6 \\
\hline 06 & 6,8 & 78 & 19,2 & SW 1,5 & S 2,3 & 0,0 \\
\hline 12 & 0,5 & 89 & 21,1 & $\mathrm{~N} 0,7$ & $\mathrm{~N} 0,5$ & 0,0 \\
\hline 13 & 3,3 & 78 & 22,0 & N 2,3 & $\mathrm{N} 0,8$ & 0,0 \\
\hline 15 & 4,0 & 88 & 22,8 & $\mathrm{~N} 1,0$ & $\mathrm{~N} 0,3$ & 0,0 \\
\hline 16 & 14,8 & 74 & 21,8 & $\mathrm{~N} 1,0$ & $\mathrm{~N} 0,3$ & 0,0 \\
\hline 26 & 5,4 & 85 & 22,6 & $\begin{array}{lll} & \text { NW } & 0,7\end{array}$ & E 1,6 & 0,0 \\
\hline 27 & 9,4 & 81 & 23,4 & $\mathrm{~N} 1,6$ & N 3,5 & $\mathrm{N} 0,3$ \\
\hline Total & 66,2 & - & - & - & - & - \\
\hline \multicolumn{7}{|c|}{ Novembro } \\
\hline 02 & 62,0 & 77 & 22,1 & NE 3,3 & $\mathrm{~N} 2,1$ & 0,0 \\
\hline 07 & 20,1 & 93 & 19,5 & $\mathrm{~N} 0,5$ & S 0,7 & S 0,5 \\
\hline 08 & 0,6 & 86 & 18,3 & S 2,5 & S 0,3 & $\mathrm{~N} 0,5$ \\
\hline 13 & 6,0 & 73 & 22,4 & W 0,8 & W 2,3 & NE 0,5 \\
\hline 15 & 0,1 & 84 & 19,3 & NE 0,7 & N 2,1 & $\mathrm{N} 0,8$ \\
\hline 17 & 0,3 & 87 & 21,3 & NE 2,5 & N 2,5 & No, 3 \\
\hline 18 & 42,6 & 94 & 22,2 & N 2,3 & N 1,5 & 0,0 \\
\hline 19 & 11,5 & 96 & 21,6 & $\mathrm{~N} 0,8$ & N 0,7 & $\mathrm{~N} 0,3$ \\
\hline 20 & 19,9 & 81 & 21,3 & N 0,7 & N 0,7 & E 0,3 \\
\hline Total & 163,1 & - & - & - & _ & - \\
\hline
\end{tabular}

A altitude influencia as diferenças de temperatura dentro da bacia, além de seus mecanismos de evaporação e da forma com que a precipitação é captada. Outra influência relacionada a altas altitudes é a retenção maior de umidade, com formação de neblinas gerando microclimas. Para melhor distribuição do uso do solo na bacia, é importante que se observem as áreas elevadas e declivosas, para uma melhor adequação da aptidão das terras. Dessa forma, tal distribuição poderá ser útil para um planejamento ou manejo da bacia em questão.

Tabela 2 - Parâmetros morfométricos da bacia hidrográfica do córrego Romão dos Reis

Table 2 -Morphometric parameters of the hydrographic watershed of Romão dos Reis stream

\begin{tabular}{lcc}
\hline Parâmetro & Unidade & Valor \\
\hline Área da bacia & ha & 230 \\
Ordem & & 2 \\
Densidade de drenagem & $\mathrm{km} / \mathrm{km}^{2}$ & 1,69 \\
Fator de forma & & 0,5368 \\
Índice de compacidade & & 0,4117 \\
Orientação & & Oeste \\
\hline
\end{tabular}

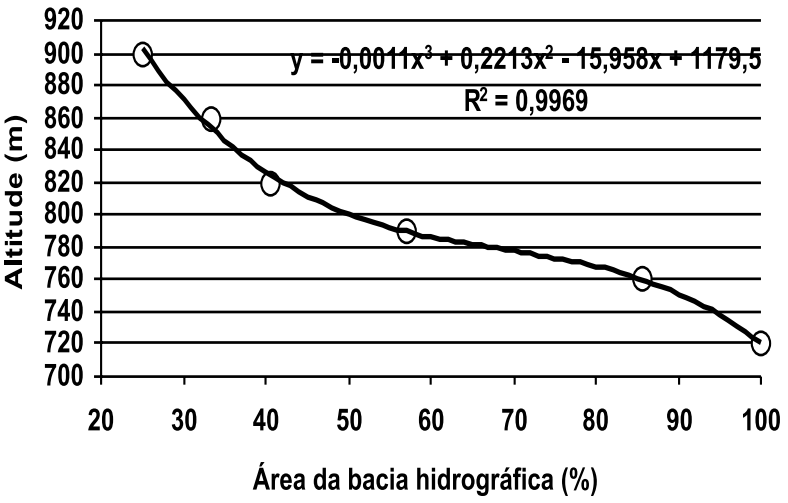

Figura 6 - Gráfico de distribuição hipsométrica da bacia hidrográfica do córrego Romão dos Reis, Viçosa, MG, 2004

Figure 6-Graph showing the hypsometric distribution of the hydrographic watershed of Romão dos Reis stream, Viçosa, MG, 2004

\subsection{Aspectos da qualidade da água}

Os resultados concernentes à qualidade da água das sub-bacias são representados na Tabela 3 .

R. Árvore, Viçosa-MG, v.31, n.5, p.931-940, 2007 
Tabela 3 - Parâmetros qualitativos da água da Bacia Hidrográfica do córrego do Romão dos Reis, Viçosa-MG, 2004 Table 3 - Qualitative parameters of water from the hydrographic watershed of the Romão dos Reis streamlet, Viçosa, MG, 2004

\begin{tabular}{cccccc}
\hline Local & $\mathrm{OD} \mathrm{mgO}_{2} / \mathrm{L}$ & $\begin{array}{c}\text { Condutividade } \\
\mu \text { S/cm a 25 T }\end{array}$ & Temp. ${ }^{\circ} \mathrm{C}$ & $\mathrm{pH}$ & TurbidezUNT \\
\hline Sub-bacia 0 & 6,14 & 38,3 & 30,4 & 7,25 & 21,6 \\
Sub-bacia 0 & 7,44 & 59,5 & 25,4 & 7,59 & 5,11 \\
Sub-bacia 1 & 9,60 & 60,4 & 22,8 & 7,95 & 4,67 \\
Sub-bacia 2 & 9,27 & 79,7 & 24,7 & 8,16 & 3,05 \\
Sub-bacia 3 & 9,01 & 38,9 & 26,7 & 7,67 & 10,9 \\
\hline
\end{tabular}

O oxigênio dissolvido (OD) é fator determinante para a manutenção dos organismos aeróbios, e a sua quantidade necessária varia de uma espécie para outra. Por exemplo, os peixes necessitam de $4 \mathrm{mg} / \mathrm{L}$, em média, para sua sobrevivência. Um dos principais fatores determinantes do OD é a atividade biológica, em que, com o seu consumo de $\mathrm{O}_{2}$, o menor número ocorreu na área onde existe piscicultura (sub-bacia 0, com 6,14 $\mathrm{mg} / \mathrm{l})$. A maior temperatura também contribuiu nesse sentido, visto que o OD depende basicamente da temperatura, salinidade e pressão do meio.

As concentrações de sólidos totais dissolvidos e a salinidade são representadas pela condutividade. Quanto maior for a concentração iônica, maior será a capacidade em conduzir corrente. Em águas naturais, podem ser encontradas faixas de condutividade na ordem de 10 a $100 \mu \mathrm{S} / \mathrm{cm}$. Em alguns casos, ela age como indicadora da poluição das águas. $\mathrm{O}$ maior número apresentado na sub-bacia 2 pode estar associado a práticas inadequadas, como a queima de pasto em área altamente declivosa, além da ocorrência de desmatamento no topo do morro.

O potencial hidrogeniônico da água é a medida da atividade dos íons hidrogênio e expressa as condições ácidas $(\mathrm{pH}<7)$ ou alcalinas $(\mathrm{pH}>7)$. $\mathrm{O} \mathrm{pH}$ adequado para manutenção de vida no meio aquático situa-se entre 6 e 9 . Todas as análises indicam valores nessa faixa e, por conseguinte, dentro da normalidade. O maior valor na sub-bacia 2 é atribuído à maior atividade fotossintética, consumindo o $\mathrm{CO}_{2}$.

Segundo von Sperling (1996), a turbidez define a alteração na penetração da luz em uma amostra da água, causada por partículas em suspensão, material coloidal, plâncton e outros organismos microscópicos. Entretanto, a cor da água é função tanto da presença de íons metálicos (principalmente Fe e Mn) quanto de húmus (ácidos húmicos) e pequenas partículas (argilas e colóides), plâncton, algas e resíduos, parte dos quais pode ser removida por filtração. Os locais que apresentaram maiores índices de turbidez (sub-bacias 0 e 3) foram os de maior atividade agrícola: um de cultivo familiar, com plantios anuais (sub-bacia 0), e outro com cultivo comercial de café (sub-bacia 3). Para o padrão de potabilidade brasileiro quanto à turbidez (menor que 5 UNT), esses índices são altos, porém de fácil tratabilidade.

A cor é um parâmetro estético e o valor-limite para o consumo humano, menor que $15 \mathrm{uH}$. Caso fosse avaliada somente a cor da água da microbacia, nenhuma poderia ser consumida diretamente, o que, entretanto, acontece. Devido a esse elevado valor, o consumo de cloro usado no tratamento aumenta. Dessa forma, a sub-bacia 0 sofre contaminação no curso de água, que chega através dos encanamentos de esgoto doméstico, que é jogado diretamente no córrego. Um dos proprietários indica como solução do problema a viabilização de ação conjunta dos moradores e instituições, na assessoria e prestação de auxílio técnico, bem como o apoio de programas ou projetos que lidam com a questão.

Mesmo sendo a produção agrícola voltada para o consumo familiar, a área possui grande potencial para a implantação de sistemas agroflorestais, cuja finalidade é garantir a diversificada produção ao longo do ano, bem como aumentar a circulação de nutrientes no sistema e evitar grandes perdas do solo por aceleração do processo erosivo, que também é um dos problemas existentes.

Na sub-bacia 1, com a intensificação da pastagem ocorre a degradação da área, causada por animais que compactam o solo, impedindo uma maior infiltração da água. Nesse caso, pode ser empregada a técnica 
de construção de sulcos em níveis para permitir que a água percorra o sistema em maior tempo, com a finalidade de melhorar o abastecimento do lençol freático e diminuir as inundações.

Na sub-bacia 2, em decorrência do desenvolvimento local, o número de casas vem crescendo de forma acelerada, o que pode prejudicar a capacidade das nascentes no abastecimento de todas as residências. Além disso, a ampliação da quantidade de fossas sépticas concentradas num mesmo local e, até mesmo, a indefinição do local apropriado, gera contaminação do curso de água. Além disso, a sub-bacia 2 apresenta alto grau de degradação, em razão de não possuir Áreas de Preservação Permanente no topo do morro e em área com declividade acima de $45^{\circ}$. Com isso se observou avançado padrão de erosão nas estradas e grandes voçorocas no pasto.

A sub-bacia 3 proporciona a maior contribuição de água da bacia, apresentando a quantidade mais alta de vazão. Entretanto, a qualidade da água pode estar comprometida, por se tratar de uma região onde se utilizam grande quantidade de insumos agrícolas no plantio comercial e convencional de café. Somente o manejo diferenciado no plantio poderia interferir, por exemplo a adoção de práticas conservacionistas como o cultivo de café orgânico.

Para aumentar a permanência da água da chuva na sub-bacia, é importante que se construam canaletas e seus devidos depósitos de contenção, direcionando o dreno. Outras práticas podem ser utilizadas, como o terraceamento ou o sulcamento de acordo com a declividade.

\section{CONCLUSÕES}

A bacia pode ser compreendida como um sistema que se apresenta sob muitas formas, o que a torna complexa. Apontar alguma indicação para seu manejo é tarefa difícil, pois, partindo apenas do ponto de vista técnico, não implica melhor decisão. No entanto, algumas práticas devem ser adotadas, emergencialmente, no caso de desgaste e perda de energia no ecossistema.

Neste estudo, foi possível realizar uma análise ordenada dos fatores socioambientais da região, possibilitando estabelecer relações entre eles. Uma intervenção na área deve levar em consideração tais fatores, a fim de possibilitar um manejo adequado, voltado para a sustentabilidade dos recursos naturais.
O uso inadequado do solo requer mudanças no sentido de sua melhor conservação, sendo o primeiro passo evitar as queimadas, comumente adotadas como práticas agrícolas na bacia. $\mathrm{O}$ alcance de um nível de organização social entre os moradores voltado para a gestão da bacia possibilitaria tais mudanças, melhorando ainda a qualidade da água.

As Áreas de Preservação Permanente (APPs) são respeitadas em quase toda a bacia, porém ainda existem trechos que necessitam de restituição. Grande parte das bordas do córrego precisa de suas florestas naturais para evitar o assoreamento, que é acelerado com a localização das estradas, bem como de outros benefícios.

A situação em que se encontram os pastos afeta a bacia, uma vez que a maioria está localizada em áreas de relevo ondulado a forte-ondulado e, conseqüientemente, com elevada predisposição à erosão. Nesses locais, o aumento da biomassa vegetal com plantio de árvores é uma medida adequada e não afeta a atividade. Esse plantio pode ser feito em faixas de retenção.

Alternativas de destino para os efluentes domésticos constituem, também, medida para melhorar a qualidade da água e diminuir gastos em seu tratamento para abastecimento da cidade.

É importante ressaltar, portanto,que, para a melhor forma de intervenção na área, necessária se torna a interação entre os aspectos econômico, ambiental e cultural, uma vez que interferirão no grau de organização e união dos proprietários das terras e moradores da bacia hidrográfica do córrego Romão dos Reis.

O tempo gasto para o diagnóstico não foi suficiente para uma completa análise dos movimentos hídricos e de toda a dinâmica envolvida na bacia. Portanto, este estudo constitui-se em um apoio para pesquisas futuras.

\section{REFERÊNCIAS}

ANIDO, N. M. R. Caracterização hidrológica de uma microbacia experimental visando identificar indicadores de monitoramento ambiental. 2002. 69f. Dissertação (Mestrado em Recursos Florestais) - Escola Superior de Agricultura Luiz de Queiroz, São Paulo, 2002.

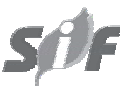

R. Árvore, Viçosa-MG, v.31, n.5, p.931-940, 2007 
ARCOVA, F. C. S.; CICCO, V. Qualidade da água de microbacias com diferentes usos do solo na região de Cunha, Estado de São Paulo. Scientia Forestalis, n.56, p.125-134, 1999.

COGO, N. P. Conceitos e princípios científicos envolvidos no manejo de solos para fins de controle da erosão hídrica. In: CONGRESSO BRASILEIRO DE CIÊNCIA DO SOLO, 21.,1987 Campinas. Anais...Campinas: Sociedade Brasileira de Ciência do Solo, 1988. Part 1. p.253-262.

\section{DEPARTAMENTO NACIONALDE} METEREOLOGIA. Normais Climatológicas (1961 a 1990). Brasília: 1992. 84p.

FERREIRA, D. A. C.; DIAS, H. C. T. Situação atual da mata ciliar do ribeirão São Bartolomeu em Viçosa, MG. Revista Arvore, v.28, n.4, p.617-623, 2004.

\section{GOLFARI, L. Zoneamento ecológico do} Estado de Minas Gerais para reflorestamento. Belo Horizonte: Centro de Pesquisa Florestal da Região do Cerrado - projeto de desenvolvimento de pesquisa florestal, 1975. 65p. (Série Técnica, 3)

LIMA, W. P. Princípios de hidrologia florestal para o manejo de bacias hidrográficas. Piracicaba: Escola Superior de Agricultura Luiz de Queiroz, 1986. 242p.

OLIVEIRA, R.D.; OLIVEIRA, M.D. Pesquisa social educativa: conhecer a realidade para poder transformála. In: BRANDÃO, C. R. Pesquisa participante. 2 ed. São Paulo: Brasiliense, 1982. p.17-33.
PINTO, L. V. A. et al. Estudo da vegetação como subsídios para propostas de recuperação das nascentes da bacia hidrográfica do Ribeirão Santa Cruz, Lavras, MG. Revista Árvore, v.29, n.5, p.775-793, 2005.

RANZINI, M. Modelagem hidrológica de uma microbacia florestada da Serra do Mar, SP, com o modelo TOPMODEL - simulação do comportamento hidrológico em função do corte raso. 2002. 116f. Tese (Doutorado em Ciências da Engenharia Ambiental)-Universidade de São Paulo/ Escola de Engenharia de São Carlos, São Carlos, 2002.

TONELLO, K.C. Análise hidroambiental da bacia hidrográfica da Cachoeira das Pombas, Guanhães, MG. 2005. 69f. Dissertação (Mestrado em Ciência Florestal) Universidade Federal de Viçosa, Viçosa, MG, 2005.

VIVAN, J. Agricultura \& florestas: princípios de uma interação vital. Guaíba: Agropecuária, 1998. 207p.

von SPERLING, E. Qualidade da água. Brasília: Associação Brasileira de Educação Agrícola Superior; Viçosa, MG: Universidade Federal de Viçosa, Departamento de Engenharia Agrícola, 1996. 59 p. (ABEAS - Curso de Gestão de Recursos Hídricos para o Desenvolvimento Sustentado de Projetos Hidroagrícolas. Módulo 3).

WISLER, C. O.; BRATER, E. F. Hidrologia. 2.ed. Rio de Janeiro: Livro Técnico, 1964. 484p. 